\title{
Correction to: Development of an Educational Device Based on a Legacy Blood Centrifuge
}

Mohamed Abdelkader Aboamer

\section{Correction to: \\ Chapter "Development of an Educational Device Based on a Legacy Blood Centrifuge" in: R. Silhavy (Ed.): Artificial Intelligence and Bioinspired Computational Methods, AISC 1225, https://doi.org/10.1007/978-3-030-51971-1_11}

In the original version of the book, the following belated correction has been incorporated:

In Chapter 11, the affiliation of author Mohamed Abdelkader Aboamer has been changed from "Department of Medical Equipment, Faculty of Applied Science, Majmaah University, Abha, Saudi Arabia" to "Department of Medical Equipment Technology, College of Applied Medical Sciences, Majmaah University, Al Majmaah 11952, Saudi Arabia".

The book and the chapter have been updated with the change. 